\title{
Pornography Use by Kinky Gay Men: A Qualitative Approach
}

\author{
Liam Wignall \\ Bournemouth University (UK) \\ liamwignall@gmail.com
}

\begin{abstract}
This study examines how kinky gay men consume and engage with pornography. Drawing on 28 in-depth interviews with self-identified kinky gay men, this study examines how pornography was discussed as a useful tool for exploring sexuality. Pornography consumption was complex and played an important role in the development of kink desires for almost all participants, being used to: explore sexual kinks; learn how to perform activities safely; and help consolidate sexual desires. Limitations and implications of this study are considered, particularly regarding the conceptual framing of pornography consumption and considerations for the future with kinky individuals.
\end{abstract}

\section{Introduction}

The study of pornography is contentious and complex (McNair, 2013), with research typically examining the potential harms of pornography use, such as negative views towards women or the potential for pornography addiction. The assumptions inherent in these types of questions still proliferate despite research repeatedly indicating the negative consequences of framing pornography through a lens of risk (Ley, Prause \& Finn, 2014; Williams et al., 2017) as well as the lack of any correlation between pornography and addiction (Kohut, Baer \& Watts, 2016; Træen, Spitznogle \& Beverfjord, 2004). The cultural harm narrative attached to pornography is viewed as detrimental not only when pornography is actively sought out (Ybarra \& Mitchell, 2005), but even when it is viewed unintentionally (Wolak, Mitchell \& Finkelhor, 2007). The assumption in research that pornography negatively affects individuals' behaviors and attitudes towards sex has been called the negative effects paradigm (McCormack \& Wignall, 2017).

Research is beginning to move beyond this paradigm and related frameworks of risk to instead explore alternative perspectives on pornography (e.g. Neville, 2018; Randall \& McKee, 2017; Thomas, 2016) such as recognizing pornography as a form of entertainment or a visual artifact to be analyzed. In an earlier article, we advocated the use of a leisure framework to research pornography (McCormack \& Wignall, 2017).

Drawing on various disciplines and established theories, leisure science researches leisure experiences - these can include activities, spaces or times (Kleiber, Walker \& Mannell, 2011). A leisure framework has been usefully applied to kink behaviors, understanding kink as an activity individuals engage in, and recognizing the unique space in which it occurs (see Williams \& Prior, 2015). Moreover, a key element of leisure is that it is intrinsically motivated and noncoerced—something which is stressed in relation to kink engagement (Pitagora, 2013). 
A leisure framework can be applied to pornography: individuals are intrinsically motivated and freely choose to interact with pornography; it is an activity which users often devote special time to in a private space (McCormack \& Wignall, 2017). The utility of this framework for pornography is that it recognizes how pornography can be personally meaningful for its users, demonstrating benefits reminiscent of other leisure pursuits (Stebbins, 2015). A leisure framework caters to an alternative discourse about pornography, which acknowledges both the potential risks and benefits of engaging in such activities for the practitioner and society. This perspective has already been effectively used to study sexual practices, such as sex in later life and kink practices (Berdychevsky \& Nimrod, 2017; Prior \& Williams, 2015; Wignall \& McCormack, 2017; Wignall, 2017).

This study moves beyond the negative effects paradigm, addressing the gap in knowledge of how individuals with kink interests interact with pornography. Specifically, the research will address how and why pornography is used by participants in relation to their kink desires and explorations.

\section{Methods}

This study was part of a broader project researching the experiences of gay and bisexual men who identify as kinky but differ in their levels of immersion in kink subcultures. For this study, I draw on 28 semi-structured, in-depth interviews with self-identified gay men ranging in ages from 21 to $62(M=27.6)$. Three participants identified as non-white and twenty-five as Caucasian. All participants were UK residents at the time of data collection. Participants identified with various roles within kink subcultures, including leather, dominant, switch, and pup.

I created a profile on geolocation "hook up" apps and socio-sexual networking sites aimed at gay and bisexual kinky men to recruit participants. A message providing details of the research was sent to prospective participants, with further information given if interest was displayed. I used established connections with prominent members in various kink communities to act as references for participants as well as for snowball sampling.

Interviews covered a range of topics related to kink identities, communities, and activities, as well as participants' interactions with kink websites. Pornography was not initially a focus of the interviews but was explored further given the central role it played for most participants. The themes presented in the following sections were not the result of questions about pornography but questions around discovering kink interests, exploring kink desires, and engagement in kink communities, with follow-up questions about pornography related to participants' initial responses. All interviews were analyzed using a modified-grounded theory approach (Charmaz, 2014), and data were coded into themes.

\section{Results}

Pornography was central to these kinky gay men’s sexual lives. While pornography consumption ebbed and flowed in their sexual lives, 25 participants spoke about its importance for discovering and exploring sexual desires. The dominant narrative was that while perusing the 
links found on vanilla pornography sites, participants discovered kinky pornography-which then led them to the types of kinky pornography that they found most appealing. Given that the interview questions focused on sexual history and practice, and not pornography per se, its centrality is an important finding in and of itself.

\section{The Role of Pornography in Discovering Initial Kink Interests}

When participants were asked questions about their general routes into kink (e.g., when did your kink desires first develop?), pornography was highlighted as a dominant path for 19 participants. These participants gave a strong narrative of "stumbling” upon kinky pornography. Participants described having kinky videos suggested to them while watching non-kinky pornography on tube websites or peer-to-peer platforms. For example, when asked where his kink interests began, Oliver said:

Looking at porn aged 11 or 12, I had too much access to the internet. It was kinky porn I was watching. It tumbled from vanilla porn and then you get to the more interesting porn... I don't know what I was thinking; maybe that it was more interesting than the other stuff.

Similarly, Peter said:

When I was coming of age, so was peer-to-peer networking, and you could have easy access to other peoples' porn. I downloaded porn, saw random videos I wouldn't normally come across, and then just liked it... I moved to more restrained [bondage] and kinky porn. Some people might have thought it too much, but I wanted to see how far I would go getting aroused by it... It was just exploring.

Pornography was described by some participants as a "stepping-stone" from vanilla to kink. For example, discussing how he first explored kink activity, Connor said, "Most of my exploration of kink online came by accident. You'd start to watch a [kinky] clip, see where it came from, click that site and just go on." Similarly, Max said, "I started viewing pornography in general, women and men. I just started exploring unusual things too.... If you're on porn and you get the lists on the side with the categories, you just have a look at them all.”

Some participants discovered their interests in kink through other routes, but no participant stated that pornography was harmful. Contrary to fears of accidentally viewing extreme pornography (Wolak et al., 2007), participants did not express surprise or offense with the content of the suggested videos. Furthermore, no participant expressed concerns with the suggested videos. Instead, the videos were normally described as "interesting" or "feeding curiosity.” Moreover, some participants praised pornography for giving them a route into kink and allowing them to explore their sexuality more fully in a safe environment.

\section{Using Pornography for Behavioral Exploration of Kink Interests}

After discussions around how participants were first introduced to kink, I asked how

participants explored their kink desires. Although participants discussed several methods, such as 
engaging with others or exploring online forums, the majority of participants also discussed using pornography as a tool for exploration of kink desires. Participants highlighted the ease with which they could use pornography to explore a wide variety of kinks in a safe environment, free from perceived social stigma, and at their own pace.

After narratives of stumbling across kink porn, participants described a move toward more focused searches to things that particularly piqued their interest. For example, Brian said, "I just watched different things online, and then you see how you feel once you have watched it." He added, "I intentionally looked for different things. Like, let's look up some guys in leather and download them and see what I think, then seeing which videos sparked an interest or not-I don’t know if I am going to like it or not until I view it.”

Brian’s narrative highlights a naiveté surrounding kink. While he used initial interests to search for more videos, he was still unsure what he liked and actively sought out new material. Furthermore, his narrative highlights a level of playfulness in searching, much in the same way an individual would try different foods to explore their palette. Brian "praised porn" for allowing a space to explore his desires at his own pace and in private. Anthony also discussed how he began to use pornography as a tool for more focused searches, stating, "You get older and watch more porn videos online and refine your searches more and realize that's what you're into... General exploring moved into more focused.”

Gabe highlighted how he considered pornography to be a platform to engage in solo exploration, saying, "It was easier to explore my interest through porn, and because I'm not always the most confident of people, it is easier to explore these things through an impersonal medium.” The lack of another person present meant Gabe could explore kink at his own pace, with no pressure to engage in any kink acts. He said, "That was one of the important things [about watching porn]: I could stop when I wanted.” Arguably, exploring through pornography may have delayed the initial onset of Gabe's first kink experience, preparing him more for when it did occur.

The benefit of exploring kink without the fear of judgement or stigma was echoed by Connor. He expressed concerns about exploring kink as an older gay man. These concerns stemmed from early experiences with sex. For example, he said, "Before the internet, the other way [of exploring and having sex] was cottaging and saunas - it tended to be quickies with no real chance of developing things.” For Connor, pornography allowed for an easier "journey into kink.” He added, "Without it, I wouldn't be where I am now, members of these clubs and this exploration, etc.”

For two participants who described early arousal to specific kinks, pornography provided a place to explore their desires more. Dan, who had a foot fetish from four years old, described the ease with which he could explore his interest, saying, "It's not difficult to come across kink: when you go online to look at porn, they will throw suggestions on the side to keep you on the site." Similarly, Justin, who was tied up by friends when he was seven, said, "You see one video in the [suggested] links, then another one, and it just snowballs into the kinky porn after a while. I never just actively outright searched it at first, but it developed.” 
Trevor was introduced to kink through a friend who invited him to a kink event. He described going to pornography afterwards as a place to further explore kink at a pace that suited him. He was able to explore a variety of kinks and discover his own interests: "I was watching more porn than I had ever watched in my entire life. More bareback, group, and kinky porn really. It looks more naughty and intimate; they look into each other. The kinky porn was just better-I find it hot.” Trevor's description of kinky pornography as "naughty” highlights an understanding of the subcultural nature of kink - a feeling that what he is doing is somehow wrong and different from what everybody else does. He may have chosen to explore kink more through pornography than attending other kink events for this reason.

Josh, who was also introduced to kink through another person, similarly used pornography afterwards to explore kink more thoroughly. He said, "I went away looking for porn after having [kinky] introductions to sex... There is a lot of things that feeds my sexual [kinks] through casual watching of porn.” Josh's initial perception of kink was very Old Guard (see Rubin, 1998) and he labelled kink as "dirty and seedy.” However, his perceptions of kink and the meanings he ascribed to kink changed through exploring pornography. Kink for Josh now means “a selection of sexual extras or additions I am into." As Trevor notes, through porn, he has a "better understanding of what [he is] into."

\section{Benefits of Interacting with Pornography}

Participants framed their pornography use as unproblematic, with some participants emphasizing the benefits of pornography by introducing them to kink and helping them explore their kink desires. While it should be emphasized that pornography is not an accurate representation of kink or sex more generally, it should be recognized as a resource being used by individuals to explore their sexuality (see also McCormack \& Wignall, 2017).

The ways in which participants describe their pornography use is reminiscent of other leisure activities. For some, pornography use was an "immediately, intrinsically rewarding, relatively short-lived pleasurable activity requiring little or no special training to enjoy it” (Stebbins, 1997, p. 18) while others invested time and energy into using pornography to explore their kink desires. Indeed, for some, pornography was a tool for engaging with a broader kink subculture.

Ethan spent time living abroad where he had little access to kink in person. Pornography on a blog was useful to help him exploring kink interests and also to "keep him in the loop" about kink. He said:

There was a blog site I used to read, a guy’s experiences of kink and such. I wasn't wanking to it really, but it was very interesting to read. I used it to learn about kinky sex, find out what existed, etc. The blog gave an indication that there was this subculture, people into it, there were places they went, roles, etc. He talked about all his experiences... I was living vicariously.

Ethan was exploring kink as well as the broader kink subculture through the blog. 
Other participants highlighted benefits of engaging with pornography, such as interacting with an online community. For example, Luis created videos on YouTube related to foot fetishism. While these videos did not display nudity or sexual practices, Luis deemed these videos to be pornographic as he knew "other people would tell him they cum to them.” He said, "I created a YouTube account at 18, a fetish based one, and started to get lots of follows, views and comments... I still use YouTube now to post videos and talk to people.” Through YouTube, Luis was able to explore his kinks, but also interact with a broader kink community.

Oliver was the only participant who actively dismissed the use of porn, regardless of its platform, as a means for exploring kink. He said, “The nitty gritty kinks you don't need to explore in porn.” Instead, he focused more on Old Guard kink traditions, where kink was something that had to be experienced and that could only be done through active engagement with others. Oliver works in a kink-based sex shop and deals with a wide range of individuals with kink interests, which may inform his standpoint.

\section{Conclusion}

Pornography use can be understood through the paradigm of leisure. Rather than the participants passively watching pornography, it was described as being actively consumed and used in multifaceted ways, intensifying kink interests by some and providing a platform for exploration by others. Although research has acknowledged pornography as a tool for exploring sexuality (e.g., Rothman et al., 2015), it has neglected the educational aspects of pornography. This study demonstrates how participants identified their kink interests in a safe space online before engaging in activities in person. As such, watching kinky pornography may have delayed or prevented engagement in kink activities (McCormack \& Wignall, 2017).

Participants' descriptions of pornography are reminiscent of other leisure experiences: they engaged in the activity in a specific space, often described as a safe space; they dedicated time for their pornography viewing; and they described positive feelings after watching it. This study supports moving beyond the negative effects paradigm and framing pornography as a leisure experience.

Watching pornography may have had a positive impact on sexual behaviors by preventing potential sexual mistakes and allowing a space in which to explore sexuality; however, more research would be needed to see if this pattern is consistent in a broader population. The dominant narrative of kink assumes the activities are performed in person (Rubin, 1991; Zambelli, 2017) with little research on understanding the role of pornography for kink practitioners (Randall \& McKee, 2017). Further research needs to be conducted to understand how pornography is used within other kink subcultures.

\section{References}

Berdychevsky, L., \& Nimrod, G. (2017). Sex as leisure in later life: A netnographic approach. Leisure Sciences, 39(3), 224-243. http://doi.org/10.1080/01490400.2016.1189368.
Charmaz, K. (2014). Constructing grounded theory. Thousand Oaks, CA: Sage.

Kleiber, D., Walker, G., \& Mannell, R. (2011). A social psychology of leisure (2nd ed.). State College, PA: Venture. 
Kohut, T., Baer, J. L., \& Watts, B. (2016). Is pornography really about "making hate to women”? The Journal of Sex Research, 53(1), 111. http://doi.org/10.1080/00224499.2015.1023427.

Ley, D., Prause, N., \& Finn, P. (2014). The emperor has no clothes: A review of the 'pornography addiction' model. Current Sexual Health Reports, 6(2), 94-105. https://doi.org/10.1007/s11930-014-0016-8.

McCormack, M., \& Wignall, L. (2017). Enjoyment, exploration and education: Understanding the consumption of pornography among young men with non-exclusive sexual orientations. Sociology, 51(5), 975-991. https://doi.org/10.1177/0038038516629909.

McNair, B. (2013). Porno? Chic! London, England: Routledge.

Neville, L. (2018). Girls who like boys who like boys. London, England: Palgrave.

Pitagora, D. (2013). Consent vs coercion: BDSM interactions highlight a fine but immutable line. The New School Psychology Bulletin, 10(1), 2736.

Prior, E., \& Williams, D. (2015). Does BDSM power exchange among women reflect casual leisure? An exploratory qualitative study. Journal of Positive Sexuality, 1, 12-15.

Randall, R., \& McKee, A. (2017). Becoming BDSM in an online environment. In P. Nixon and I. Düsterhöft (Eds) Sex in the digital age (pp. 168178). London, England: Routledge

Rubin, G. (1991). The catacombs: A temple of the butthole. In M. Thompson (Ed.) Leatherfold: Radical sex, people, politics and practice (pp. 119-141). Boston, MA: Alyson.

Rubin, G. (1998). Old guard, new guard. Cuir Underground, 4.2. Retrieved September 25, 2018 from: http://www.evilmonk.org/a/grubin.cfm

Rothman, E., Kaczmarsky, C., Burke, N., Jansen, E., \& Baughman, A. (2015). "Without porn... I wouldn't know half the things I know now”: A qualitative study of pornography use among a sample of urban, low-income, black and Hispanic youth. The Journal of Sex Research, 52(7), 736-746.

https://doi.org/10.1080/00224499.2014.960908.
Stebbins R. (2015). The serious leisure perspective. In: Leisure and Positive Psychology: Linking Activities with Positiveness. London, England: Palgrave Macmillan

Stebbins, R. (1997). Casual leisure: A conceptual statement. Leisure Studies, 16, 17-25. https://doi.org/10.1080/026143697375485.

Træen, B., Spitznogle, K., \& Beverfjord, A. (2004). Attitudes and use of pornography in the Norwegian population 2002. The Journal of Sex Research, 41(2), 193-200. https://doi.org/10.1080/00224490409552227.

Thomas, J. (2016). The development and deployment of the idea of pornography addiction within American Evangelicalism. Sexual Addiction \& Compulsivity, 23(2-3), 182-195. https://doi.org/10.1080/10720162.2016.1140603.

Wignall, L. (2017). The sexual use of a social networking site: The case of pup twitter. Sociological Research Online, 22(3), 21-37. https://doi.org/10.1177/1360780417724066.

Wignall, L., \& McCormack, M. (2017). An exploratory study of a new kink activity: "Pup play.” Archives of Sexual Behavior, 46(3), 801811. https://doi.org/10.1007/s10508-015-0636-8.

Williams, D., \& Prior, E. (2015). "Wait, go back, I might miss something important!” Applying leisure 101 to simplify and complicate BDSM. Journal of Positive Sexuality, 1(3), 63-69.

Williams, D., Thomas, J., Prior, E., Wright, S., Sprott, R., et al. (2017). Sex and pornography "addiction." Journal of Positive Sexuality, 3, 4043.

Wolak, J., Mitchell, K., \& Finkelhor, D. (2007). Unwanted and wanted exposure to online pornography in a national sample of youth Internet users. Pediatrics, 119(2), 247-257. https://doi.org/10.154/peds.2006-1891.

Ybarra, M., \& Mitchell, K. (2005). Exposure to Internet pornography among children and adolescents: A national survey. Cyberpsychology \& Behavior, 8(5), 473-486. https://doi.org/10.1089/spb.2005.8.473.

Zambelli, L. (2017). Subcultures, narratives and identification: An empirical study of BDSM (Bondage, Domination and Submission, Discipline, Sadism and Masochism) practices in Italy. Sexuality and Culture, 21(2), 471-492. https://doi.org/10.1007/s12119-016-9400-z. 